\title{
BELIGGAAMDE REALISME EN EKOBILLIKE GODSKONSTRUKTE
}

Author:

Philip P. Venter

\author{
Affiliation: \\ ${ }^{1}$ Departement van $\mathrm{Ou}$ \\ Testament Studies, \\ Universiteit van Pretoria, \\ Suid-Afrika
}

\section{Correspondence to:}

Philip Venter

e-mail:

venterp@iafrica.com

Postal address:

Posbus 73095, Fairland 2030

Suid-Afrika

\section{Keywords:}

kognitiewe wetenskap;

filosofiese denkraamwerk; oriëntasiemiddelpunt; medium; beliggaamdheid

\section{Dates:}

Received: 3 Mar. 2008

Accepted: 28 Apr. 2009

Published: 23 Oct. 2009

How to cite this article:

Venter, P.P., 2009,

'Beliggaamde realisme en ekobillike godskonstrukte Verbum et Ecclesia 30(2), Art. \#58, 6 pages. DOI: 10.4102/ ve.v30i2.58

\section{This article is available} at:

http://www.ve.org.za
(C) 2009. The Authors. Licensee: OpenJournals Publishing. This work is licensed under the Creative Commons Attribution License.

\section{ABSTRACT}

Embodied realism and congruent God constructs

The findings of modern cognitive sciences have far-reaching implications for the philosophical framework within which theological texts have been and could be interpreted. In this regard, the body presents itself as an important epistemological agent. Body-critical analysis of Bible texts provides insight into the societal and cultural factors that brought about those texts, and presents a philosophical approach of embodied realism congruent with the embodiment of thought, the cognitive subconscious and the methaphorical nature of abstract concepts. By taking the body ideology fundamental to the concepts and constructs in religious texts seriously, a new discourse can be stimulated that will bring about new embodied perspectives on the relationship between humans, the environment and other 'others'. A society that is serious about ecojustice as far as the interrelatedness of all creatures is concerned should shoulder the responsibility continuously to consider and revise its hierarchical normative paradigms. The purpose of this article is to investigate the role and place of the body in the establishment of God constructs as normative paradigms.

\section{INLEIDING}

Die bevindinge van moderne kognitiewe wetenskappe het ingrypende implikasies vir die filosofiese denkraamwerk waarin kulturele geskrifte, veral teologiese tekste, vertolk is en kan word. Dit dwing die liggaam voorop as ' $n$ uiters belangrike epistemologiese agent. In die woorde van Leder (1990:1): 'Human experience is incarnated.' Die liggaam is nooit bloot ' $n$ objek in die wêreld nie, maar die medium waardeur ons wêreld in aansyn geroep word (Leder 1990:5). Die liggaam is die oriëntasiemiddelpunt waardeur ons met ons wêreld omgaan en betekenis konstrueer. Liggaamskritiese ondersoek van die tekste in die Bybel bied ' $n$ invalshoek tot insig in die gemeenskaplike en kulturele faktore wat tot sodanige tekste aanleiding gegee het. Dit bring ' $n$ andersoortige filosofiese benadering mee, te wete ' $n$ beliggaamde filosofie wat in pas is met die beliggaamdheid van denke, die kognitiewe onbewuste, en die metaforiese aard van abstrakte konsepte. Erns met die liggaamsideologie onderliggend aan die konstrukte en konsepte in religieuse tekste sal 'n nuwe diskoers oor sogenaamde 'normatiewe' begrippe stimuleer en moontlik nuwe (beliggaamde) perspektiewe in die verhouding tussen die mens, die omgewing en ander 'andere' bring. ' $n$ Samelewing wat begaan is oor ekobillikheid wat die onderlinge verbondenheid van alle skepsele betref, het immers die verantwoordelikheid om die hiërargiese normatiewe paradigmas op grond waarvan dit funksioneer, voortdurend in oënskou te neem. Die doel van hierdie artikel is om die rol en plek van die liggaam in die vestiging van godskonstrukte as sodanige normatiewe paradigmas uit te wys.

\section{LIGGAAM, DENKE EN DIE ABSTRAKTE}

Die vernaamste empiriese bevinding van moderne kognitiewe wetenskappe is dat ons versteekte konseptuele meganismes, wat beeldskemas ('image schemata'), metafore en beliggaamde konseptuele strukture insluit, ons in 'n groot mate daartoe in staat stel om "n leefwêreld te hê'. Ons kognitiewe onbewuste speel 'n kernrol, nie net in die konseptualisering van ons leefwêreld nie, maar ook om die wêreld wat ons ervaar, te skep (Lakoff \& Johnson 1999:509). Dié bevinding kan in drie dele uiteengesit word:

- Gees is altyd beliggaam.

- Denke is meestal onbewus.

- Abstrakte konsepte is grootliks metafories.

\section{Beliggaamde gees}

Die bevinding oor die beliggaamdheid van die gees, selfs die term 'beliggaamde gees' op sigself, betwis in wese tradisionele dualismes, en trek ' $n$ streep deur die byproduk van Cartesiaanse dualisme, naamlik objektivisme. As sulks is dít goeie nuus in 'n situasie waar die Aarde juis herdefinieer moet word - as subjek beskou moet word - ten einde haar ondergang te voorkom. As gees, denke of gedagte as onbeliggaamd beskou word, word die gaping tussen denke en wêreld onoorbrugbaar, en hou dit die wrede dualisme tussen kultuur en natuur in stand.

Die beliggaamdheid van gees, denke en rede, soos die kognitiewe wetenskappe uitwys, bied 'n nuwe begrip van die verhouding tussen gedagte of denke, en realiteit: Dít kan ' $n$ beliggaamde realisme genoem word (Lakoff \& Johnson 1999:95). Beliggaamde realisme, wat die Cartesiaanse digotomie tussen denke (gees) en liggaam verwerp, is gegrond op die menslike vermoë om suksesvol in ' $n$ fisiese omgewing te funksioneer. Dus is dit ' $n$ evolusiegegronde realisme. Evolusie het ons van aangepaste liggame en breine voorsien, wat ons in staat stel om ons omgewing te omarm en selfs te omvorm. Realisme, as omgekeerde van objektivisme, gaan dus in wese oor die mens se suksesvolle funksionering in die wêreld. Iemand wat 'onrealisties' is, is ' $n$ wanaangepaste persoon - uit voeling en in disharmonie met die wêreld. Realisme behels om met die wêreld in voeling te wees op wyses wat oorlewing verseker, groei waarborg, en die verwesenliking van doelwitte inhou. Om egter só in voeling te kan wees, vereis iets wat kan 'voel', naamlik 'n liggaam. 
Konsepte, ook oorlewingskonsepte soos sogenaamde hanteringsmeganismes ('coping mechanisms'), ontstaan in en word begryp deur die liggaam, die brein, en liggaamlike ervaringe in die wêreld. Konsepte kry betekenis deur beliggaming, en veral deur persepsuele en motoriese vermoëns (Lakoff \& Johnson 1999:497). In beliggaamde realisme hang waarheid nie van een of ander eksterne rasionele konstruk, byvoorbeeld ' $n$ 'openbaring', af nie, maar van subjektiewe begrip en insig (Lakoff \& Johnson 1999:114).

In objektivistiese sienings van betekenis en rasionaliteit word die menslike liggaam, veral die struktuur van konseptualisering, verbeelding en begrip wat uit ons beliggaamde bestaan na vore kom, tot dusver grootliks geïgnoreer en onderskat. Dít is weens die oortuiging dat die liggaam ' $n$ subjektiewe element na vore bring wat nie in die objektiewe aard van betekenis ter sake is nie. Die liggaam word geïgnoreer omdat rede as abstrak en transendent, sonder enige verband met enige liggaamlike aspek van menslike begrip, beskou word. Die liggaam word geïgnoreer omdat dit klaarblyklik geen rol in ons redevoering oor abstrakte konsepte speel nie (Johnson 1987:xi). Dat hierdie gevolg van die Cartesiaanse liggaam-gees-dualisme betwis moet word, blyk uit die geweldige sosiale impak wat dit gehad het en steeds het. Die hiërargiese Cartesiaanse dualisme het die onderdukking van vroue, diere, die natuur en ander 'andere' regverdig (Leder 1990:4). Viviers (2005:883) verwoord dit soos volg: 'The body is also thrown away for the sake of the mind, and the result: an impoverished experience of life...bodies know deeper than minds alone.' Gevolglik dien die bevindinge van die kognitiewe wetenskappe om ons ons gewaande transendensie te laat oorkom, sodat ons die inherensie van ons bestaan in eenheid en vervlegting met die ganse universum kan besef. Die denkende gees en die liggaam is in werklikheid nie teenoorgestelde substansies nie, maar vervlegte aspekte van dieselfde lewende organisme. Cartesiaanse kategorieë van gees en liggaam dien bloot om ervaringsklasse wat in onophoudelike wisselwerking is en mekaar aanvul, te hervestig en te skei. Geleenthede waar die liggaam hoogs verborge en selftransendent is, val onder die kategorie 'gees'. Ander ervaringe, waar liggaamlikheid ' $n$ sterk tematiese teenwoordigheid het, val weer onder die kategorie 'liggaam'. Tog is ons as mense 'begeesterde liggame'. Ons ervaringe toon weliswaar wisselende aksente. Soms is ons hoogs bewus van onsself, en ander kere heel onbewus. Ons beleef onsself soms as wesens wat ons omgewing beïnvloed, maar voel ander kere weer grootliks uitgelewer. Soms word ons getref deur die transendensie van ons aardse bestaan; ander kere is die lewe op aarde ' $n$ dreigende, harde werklikheid. Dit is egter dieselfde liggame wat hierdie wisselende ervarings het en dit uiteindelik metaforiseer (Leder 1990:149).

Die bevinding van die vervlegtheid van gees en liggaam, oftewel die beliggaamdheid van die gees, betwis en omvorm verder alle ander dualismes wat uit dié van gees en liggaam vloei. Dit impliseer dat die beliggaamdheid van alle konsepte, soos gender, natuur, God, ensovoorts, erken en moontlik aan die hiërargieë wat daarop gebou is, ontruk moet word. Dit kan belangrike gevolge vir die herstel van vele verbrokkelde verhoudinge inhou.

\section{Onbewuste denke}

Ashbrook (1996:385-398) beskryf 'n ingrypende studie in 1987 deur Diane Jonte-Pace wat aan die hand van die Rorschach-projeksietegnieke uitgevoer is, welke studie die breingegrondheid van sowel subsimboliese as simboliese bewussyn toon. Die studie bevind dat normale menslike waarneming en funksionering ' $n$ wederkerige wisselwerking tussen die subsimboliese ('ou brein' of ouer korteks) en simboliese ('nuwe brein' of neokorteks) behels, waar die subsimboliese ons gemeenskaplike erfenis verteenwoordig - dít wat ons met elke ander wese, ongeag kultuur, klas, ras of gender, in gemeen het, terwyl die simboliese na ons unieke erfenis, die kultuurbepaalde instinkte en intuïsies verwys. Ons 'ouer brein' verbind ons met alle ander organismes; met elke deel van die fisiese universum. Die 'nuwe brein' verteenwoordig ons verwantskap aan die hand waarvan ons van sommige ander organismes onderskei word: 'The nonconscious mind attends to maintaining an inner equilibrium and our conscious mind attends to developing an outer rationale.' (Ashbrook 1996:387). Wat insiggewend is van Ashbrook se bevindinge, benewens die fisiese grondslag van ons mees subsimboliese sowel as ons eksplisiet simboliese funksionering, is eerstens die wederkerigheid of wisselwerking tussen liggaamlik bepaalde instinktiewe bewussyn en liggaamlik bepaalde kultuurvorming en -rangskikking - 'n sleutelaspek van hierdie studie - en die evolusiegegrondheid of evolusionêre aard van ons breinbewussyn: '... [T]he neocortex acts in accordance with what the older cortex determines to be necessary for the long-term survival of humanity.' (Ashbrook 1996:387) Spirituele ervaring, of waarneming uit ' $\mathrm{n}$ diepgesetelde spirituele (religieuse) paradigma, kan die subsimboliese bewussyn in 'n groot mate deoutomatiseer:

...IIIn spiritual experience, ordinary perception is deautomised and then resymbolised primarily in terms of which the particular culture used to interpret and explain the cosmos...

(Ashbrook 1996:386)

Dit kan op sy beurt tot wanfunksionering lei, aldus Diane JontePace se studie van drie verskillende godsdienstige 'meesters'. Nogtans kan daar nie aan die liggaamlike evolusionêre interaktiwiteit van breinfunksionering ontkom word nie, en bly die kognitiewe onbewuste alleen as beliggaamde bewussyn verstaanbaar.

Hierdie en ander empiriese studies oor menslike waarneming dui op ' $n$ wesenlike grondbeginsel: enige sinvolle siening van betekenis en rasionaliteit móét ' $\mathrm{n}$ kernplek aan beliggaamde en onbewuste strukture van begrip toeken waardeur ons ' $n$ greep op ons wêreld kry (Johnson 1987:xiii). Ons is produkte van evolusionêre prosesse, en ons breinfunksies 'skep' aan die hand van die wisselwerking daarvan ons nuwe bestaan in sowel die subsimboliese as die simboliese sfeer. Doelbewuste deoutomatisering van ons breinprosesse, soos in eksterne magsuitoefening deur spiritualiteit, religie en politiek, is dus kontramenslik, en dit is geen wonder dat die drie geestelike 'meesters' in Diane Jonte-Pace se studie ál drie selfs op subsimboliese vlak tekens van wanaanpassing en wanfunksionering toon nie.

\section{Metaforiese aard van abstrakte konsepte}

In die lig van die liggaam se belang in ons simboliseringsaktiwiteite, is dit voorts nodig om die beliggaamde kognitiewe prosesse waardeur ons ons wêreld konstrueer (Johnson 1987:102), in oënskou te neem. Vorster (1997a:452) voer aan dat ons nie slegs dinge rondom ons as verlenging van ons eie liggaamlikheid beliggaam nie, maar dat ons ook ons liggaamlikheid op metaforiese wyse verleng deur die konstruksie van kosmologieë of simboliese wêrelde waarin ons leef. So onderskryf ons die antieke oortuiging dat die liggaam 'n mikrokosmos van die makrokosmos is; ' $n$ kleiner weergawe van die groot wêreld (Martin 1995:16; sien ook Berquist 2002). Metaforisering is dus noodsaaklik vir ons bestaan as menslike wesens. Om te leef, is om in ons wisselwerking met die realiteit te metaforiseer, te simboliseer, en betekenis te soek en aan te voer (Viviers 2002:516). Ons beliggaamdheid lê daaraan ten grondslag.

Daar is reeds daarop gewys dat ' $n$ filosofie van beliggaamde realisme, teenoor byvoorbeeld objektivisme, hier as filosofiese uitgangspunt dien. Die besondere bydrae van moderne kognitiewe wetenskappe, wat ' $n$ nuwe deur vir diskoers oor filosofiese konsepte of 'rede-nasies' oopmaak, lê daarin dat die kognitiewe wetenskappe beliggaamde realisme empiries as uitgangspunt staaf, in teenstelling met die inherente aannames van byvoorbeeld objektivisme (Lakoff \& Johnson 1999:14, 15, 551-552). Rede, soos dit deur die liggaam gevorm word, word soos volg beskryf: 
From the commonalities of our visual systems and motor systems, universal features of spatial relations (image schemas) arise. From our common capacities for gestalt perception and motor programs, basic-level concepts arise. From the common color cones in our retinas and the commonalities of our neural architecture for color vision, the commonalities of color concepts arise. Our common capacity for metaphorical thought arises from the neural projections from the sensory and motor parts of our brain to higher cortical regions responsible for abstract thought. Whatever universals of metaphor there are arise because our experience in the world regularly makes certain conceptual domains coactive in our brains, allowing for the establishment of connections between them. The commonalities of our bodies, brains, minds and experience makes much (though not all) meaning public.

(Lakoff \& Johnson 1999:463)

In 'n vroeëre werk konsentreer Johnson (1987) op die prosesse van metaforisering en simbolisering deur die term 'image schemata' of beeldskemas te gebruik. Beeldskemas is die menslike denkgereedskap of 'hardeware' (Viviers 2002:517) waarmee ons ons ruimte orden, en betekenis toeken aan die miljoene stimuli wat ons deur ons sintuie ontvang. Natuurlik filtreer ons die massa data wat ons sintuie versamel, en aanvaar slegs dít wat ons benodig. ' $n$ Beeldskema is ' $n$ herhalende patroon of vorm in die ordeningsaktiwiteit (Johnson 1987:29). Hierdie ordeningspatrone is geheelstrukture sonder voorskrif en voor enige waarneming (Johnson 1987:44), maar is nie irrasioneel nie. In taal word hierdie patrone uiteindelik in voorskriftelike, feitelike of objektivistiese stellings geopenbaar, en dit is hierdie voorskriftelike stellings wat bepaal wat ons glo. Sulke feitelikhede of voorskriftelikhede word gewoonlik as 'geopenbaarde waarhede' beskou, maar blyk bloot die oppervlak of die buitewand van ons beliggaamde begrip te wees 'which we peel off as abstract structures' (Johnson 1987:138). Die oppervlaklaag van ons konseptuele begrippe en stellinge, en die liggaamlike bepaaldheid daarvan, is een proses, en nie ' $n$ dualisme waarvolgens eersgenoemde as ' $n$ hoër waarnemingsvorm en laasgenoemde as minderwaardig bestempel kan word nie (Johnson 1987:167-168). Liggaam en gees funksioneer as ' $\mathrm{n}$ eenheid. Beeldskemas verbind liggaamlike ervaringe, sensasies en gedagtes. Dit is eie aan die menslike vermoë om liggaamservaringe tot verdere of ander fisiese of niefisiese sfere te verleng, te vertaal en te metaforiseer. 'n Toepaslike voorbeeld is die beeldskema van balans. Ons projekteer ons liggaamlike ervaring van balans op ons dieet deur gebalanseerd te eet; ons is voorstanders van gebalanseerde stadsbeplanning en -bestuur; of ons brei die ervaring van balans na die psigologiese sfeer uit deur ons emosies 'in toom te hou' of gebalanseerd tot uiting te laat kom. Ander beeldskemas waarmee ons in dieselfde trant omgaan, is byvoorbeeld omsluiting, krag, siklusse, skakels en roetes (Johnson 1987:126).

Ons liggaamlike sensoriese en motoriese ervaringe gee aanleiding tot abstrakte konsepte, welke abstrakte konsepte dus ' $\mathrm{n}$ kwalitatiewe 'tasbaarheid' het (Lakoff \& Johnson 1999:128). 'n Sensoriese ervaring gaan dikwels deur middel van ' $\mathrm{n}$ beeldskema oor in primêre en dan meer komplekse metafore. So kan die abstrakte konsep 'gelukkig', in die sin van ' $\mathrm{n}$ emosionele hoogtepunt, afgelei word van die primêre metafoor dat 'gelukkig' op opwaartse beweging of die 'toppunt' van emosionele ervaring dui. Dit op sigself kom van die regop liggaamshouding wat op energie, gesondheid en beheer dui (Lakoff \& Johnson 1999:50). Die uitdrukkings 'my gedagtes het gedwaal' of 'idees het deur my kop gemaal', is afgelei van die metafoor 'denke is beweging', wat op sigself afgelei is van die liggaamlike belewenis van rondbeweeg om inligting te versamel (Lakoff \& Johnson 1999:236). Ook ons abstrakte konsepte oor moraliteit is in ons fisiese welsyn veranker. Ons konsep van regte, byvoorbeeld eiendomsreg, vryheid van beweging, en beskerming teen leed, is afgelei van ons fisiese ervaringe in ons kinderdae, toe ons besittings (speelgoed) gehad het of deur ' $n$ verskeidenheid ouerlike metodes teen fisieke belemmerings en pyn gevrywaar was (Lakoff \& Johnson 1999:128). Nog etlike voorbeelde kan opgenoem word om te bevestig dat ons liggame ons denke bepaal.
Volgens Johnson (1987:x) bestaan die sogenaamde 'objektiewe wêreld' uit objekte met eienskappe wat in ' $n$ verskeidenheid verwantskappe tot mekaar staan en wat onafhanklik is van menslike begrip. Die wêreld is soos dit is, ongeag wat enige persoon daaroor dink of glo. Daar is maar een korrekte, goddelike beskouing van wat en hoe die wêreld is. Daar is ' $n$ rasionele struktuur inherent in alle realiteit, en korrekte rede is die spieëlbeeld van sodanige rasionele struktuur. 'Waarheid' kan dus ontdek word deur die menslike rede met die suiwere, universele (ontliggaamde) rede te verbind. Uit die empiriese bevindinge ten opsigte van die beliggaamdheid van denke en metaforiserings blyk egter duidelik dat sogenaamde 'universele waarhede' oor die 'objektiewe werklikheid' beter verklaar kan word aan diehand vanmenslike, gedeeldeliggaamlikheid waaruit (abstrakte) wêrelde geskep word, in plaas van die objektivistiese aansprake op gegewens of realiteite 'daar buite'. 'n Beliggaamde realisme lei nie tot absolute of transendente waarhede nie, maar is ook nie ' $n$ blote relativisme nie. Dit lei tot stabiele waarhede namate mense oor kulture heen van hulle omgewings sin maak, gesamentlik beperk deur hulle gemeenskaplike liggaamlikheid (Lakoff \& Johnson 1999:6). 'n Elementêre voorbeeld wat die aanname dekonstrueer dat objekte oor eienskappe beskik wat onafhanklik is van menslike konseptualisering daarvan, is kleur. Kleur bestaan nie onafhanklik van ons breinfunksie van kleurwaarneming nie, en is ook nie ' $n$ afskynsel van die oppervlak van 'n objek nie. Deur die proses van evolusie het ons die vermoë ontwikkel om groen as kleur te 'sien', waarskynlik as bron van voedsel of beskerming. Die blou lugruim is nie die afskynsel van een of ander oppervlak nie, nogtans 'sien' mense wêreldwyd die lug as 'blou'. Kleure bestaan nie as objektiewe eienskappe nie, maar is menslike denkkonstrukte. Ons wêreld verteenwoordig skynbaar ' $n$ objektiewe werklikheid omdat ons deur ons beliggaamdheid so merkwaardig daarby aangepas het (Lakoff \& Johnson 1999:23-26).

Hierdie bevindinge, soos dit in die filosofiese konsep van beliggaamde realisme teenoor objektivisme geopenbaar word, het verreikende implikasies vir godsdienstige diskoers, en open nuwe deure vir die studie van byvoorbeeld religieuse tekste. Veral ten opsigte van godsdiens en godsdienstige konsepte, het objektivisme ' $n$ wurggreep uitgeoefen wat ons vir ons menslike subjektiwiteit verblind het. Die onafhanklike waarheidsmomente van godsdienstige 'feite', wat so kenmerkend is van ' $\mathrm{n}$ fundamentalistiese godsdiensbeskouing; dit wat as 'normaal' of 'natuurlik' bestempel word (Vorster 1998:205); die 'geopenbaarde' of 'ingegewe' waarhede, is duidelik niks anders nie as versinnebeelde produkte van ons eie liggaamlikheid. Objektivisme word dikwels in uitsprake oor God aangetref, en kom tot uiting in kategoriese uitlatings soos 'God het die man as die vrou se meerdere geskape, dit is ' $n$ natuurlike gegewe'. Vorster (1997b:409) wys daarop dat sodanige uitsprake wat wesenlike uitbeeldings vervat, die 'ononderhandelbare kwessies' van 'n gemeenskap verteenwoordig, en gewoonlik daarop gemik is om alle bespreking met ' $n$ gesaghebbende argument te beëindig. Bogenoemde voorbeeld onthul egter nie ' $n$ 'waarheid' nie, maar toon die patriargale strewe na mag en beheer. So is die 'God' van Godspraak gewoonlik ' $n$ personifieerde simbool - 'n kragtige sosiale strategie waardeur gemeenskapspraktyke beheer word; as't ware die 'gemeenskapas-god' (Vorster 2003:4). Uit samelewingsverskynsels, soos patriargie, seksisme en rassisme, word dit dan ook duidelik hoe sekere liggame met goddelike ondersteuning bo ander voorrang kry. In dié verband dien die Suid-Afrikaanse apartheidsbeleid van die twintigste eeu, en die godsdienstige onderbou wat daaraan verleen is, as kragtige voorbeeld. Die bevinding van die liggaamlike bepaaldheid van menslike metaforisering oor selfs die abstrakste konsepte, ook godskonstrukte, lê uitlatings oor God as subjektiewe, menslike metaforiserings bloot, gebore uit bepaalde liggaamlike belewenisse. Die wyse waarop sodanige metaforiserings in 'n gemeenskap gestalte kry, word vervat in die simbolisering van die liggaam as ' $n$ gemeenskap se kulturele kode of sosiale 'teks'. 


\section{DIE LIGGAAM AS SOSIALE TEKS: DIE SIMBOLIESE LIGGAAM}

Malul (2002:42) beskryf ' $n$ teks as enige groepering tekens en stimuli wat tot ons sensoria spreek om geabsorbeer te word, en wat ons stimuleer om betekenis daaraan toe te ken, dit wil sê om die boodskap wat daarin weggelê is, te ontsyfer. Die liggaam is nie slegs die immerteenwoordige realiteit wat ons kognitiewe vermoëns bepaal nie. Die liggaam as sodanig verkry ook simboliese of retoriese waarde wanneer dit as sosiale teks of kode gekonstrueer en aan die gemeenskap gebied word. 'Liggaam' as teks van die gemeenskap verwys na die simboliese liggaam van ' $n$ gemeenskap, of die idees wat ' $n$ bepaalde gemeenskap oor die liggaam daarop nahou. As kode bevestig en herbevestig die liggaam die kulturele identiteit van 'n gemeenskap.

Alvorens daar op die retoriese aard van die liggaam, of die liggaam as kulturele teks, gekonsentreer word, eers enkele opmerkings oor metafore in die algemeen. Basson (2005:31) wys op die belang van metaforisering as taalgebeure wat onder andere die waardestelsel, menslike opvattings, oriëntasies en voorkeure van ' $n$ bepaalde kultuur openbaar. Die mees grondliggende waardes van ' $n$ kultuur sal met die metaforiese struktuur van die mees grondliggende konsepte van die kultuur ooreenstem (Basson 2005:31). Die metafoor kies, beklemtoon, onderdruk en organiseer eienskappe van die primêre subjek deur stellinge daaroor te impliseer wat gewoonlik op die sekondêre subjek van toepassing is, en andersom. In die stelling: 'Only the mountains have lived long enough to listen objectively to the howl of the wolf' (Aldo Leopold, soos aangehaal deur Ahlers 1990:433) word die ouderdom van die berge ('so oud soos die berge') byvoorbeeld met die kort leeftyd van die mens in ' $n$ kosmiese sin gekontrasteer. Die menslike eienskappe van lewe, luister, objektiwiteit of goeie oordeel word weer op die berg toegepas, en die berge se opneming van hierdie menslike eienskappe bring 'n nuwe verhouding tussen die mens en die wolf tot stand - ' $n$ verhouding analoog aan die verhouding tussen die berg en die wolf (of ten minste probeer Leopold met hierdie metaforiese uitdrukking so ' $n$ ekobillike insig by mense tuisbring). Die sifting van een stel gemeenplase met ' $n$ ander bring ' $n$ nuwe konseptuele struktuur tot stand wat 'n nuwe beskouing van ' $n$ gebeurtenis of objek bied (Basson 2005:36).

Begrip van ' $n$ metafoor bring iets nuuts na vore, omdat ' $n$ metafoor ' $n$ taalgebeurtenis is wat ' $n$ skeppende reaksie uitlok. Die kognitiewe teorie van metaforisering beklemtoon dat metafore ons gedagtes deurdrenk en ' $n$ integrale deel van ons daaglikse redenering uitmaak. Metaforisering is die wyse waarop menslike wesens ondersoekend met wetenskap, godsdiens, digkuns, politiek, ensovoorts omgaan (Basson 2005:37).

Ook ' $\mathrm{n}$ gekonstrueerde liggaam as sodanig funksioneer as ' $\mathrm{n}$ metafoor/simbool om iets nuuts in die kultuur tot stand te bring. Vorster (1997a:450-453; 1997b:390) bevestig die liggaam as 'fundamentele konsep van kultuur' (om Basson se verduideliking hier bo verder te voer). In retoriek val die klem sterk op die 'persoon', en Vorster (1995:401) verbind dit dus met menslike motivering: 'Human motivation within rhetoric is not a regress into intentional fallacy, because it is open-ended and implies multiple motivations.' Hoekom doen, praat, skryf en vertolk ons soos wat ons doen? Wat motiveer ons om uit die groot omvang van simbole sekeres te kies, en ander te ignoreer of te verwerp? (Vorster 1995:400-402) Dít verleen erkenning aan ons subjektiwiteit. Die konsep 'persoon' verwys na die sosiale of verbonde aard van die liggaam (Vorster 1997b:390; Viviers 2005:880). Die dialektiek tussen liggaam en taal spruit uit die menslike wese se vermoë om te simboliseer, wat aan die liggaam sy retoriese aard verleen - wat die liggaam as't ware 'n 'stem' maak. Sodoende verkry die liggaam politieke mag (Vorster 1997b:393). 'n 'Persoon' is dus ' $n$ liggaam met mag; ' $n$ liggaam wat oor dieselfde wisselwerkings-, strukturerings- en skeppingsvermoë van taal beskik, en dus realiteite kan vorm (Vorster 1997:393). In dié verband tipeer Vorster (2000:109) die simboliese liggaam as 'n konstruksie, net soos klas, ras en gender. Hierdie beskouing staan teenoor die siening dat taal bloot ' $n$ stel simbole is wat die objektiewe werklikheid weerspieël, met min ruimte vir menslike subjektiwiteit. Vorster (1997b:393) toon hoe die liggaam van die mens se geboorte af by die diskursiewe praktyke van ' $n$ gemeenskap ingetrek en sodoende deur taal beheer word: Die liggaam word ' $n$ taaldaad; ' $n$ sosiale of kulturele teks of kode (Vorster 2002:21). 'n Gemeenskap se waardes word op en in die liggame as tekste ingegrif, dikwels verborge (Vorster 2001:441). As ' $n$ taalkonstruksie vorm en plooi hierdie kodes of tekste die aanhangers van ' $n$ bepaalde gemeenskap om die liggame te wees wat hulle behoort te wees. Hierdie liggaamsideologieë van 'n gemeenskap stem nie noodwendig met werklike vleesen-bloedliggame ooreen nie, maar is ideale konstrukte (Viviers 2005:879-880). Dit bied aan die lede van die gemeenskap voorstellinge van kultureelspesifieke subjektiwiteite of selfbegrip. Die liggaam is die produk van, én repliseer, hierdie betekeniskonfigurasies. Vorster (2002:7) gebruik die konsep habitus om hierdie betekeniskonfigurasies van ' $\mathrm{n}$ bepaalde gemeenskap, wat oor ' $n$ lang tydperk as 'objektiewe waarheid' gevestig raak, te beskryf. Hy omskryf habitus as stelsels van volhoubare, oordraagbare voorveronderstellings wat bestem is om ook vormend te funksioneer. Dit dien as beginsels wat praktyke en voorstellings teweegbring en organiseer, wat objektief aangepas kan word na aanleiding van die uitkomste daarvan, sonder ' $n$ bewuste voorafgerigtheid op die uitwerking daarvan, of sonder ' $n$ uitdruklike bemeestering van die vereiste werkinge om sodanige strukturerende beginsels te bereik. Hierdie 'feite en waarhede' fabriseer, skep en vorm die liggame van 'n gemeenskap tot die ideale liggaam wat die gemeenskap koester. Sodanige normatiewe liggaam kan as die gemeenskap se 'reguleringsliggaam' bestempel word - ' $\mathrm{n}$ status wat in die antieke wêreld aan die manlike liggaam toegeken is (Vorster 2002a:11-19; Berquist 2002:36).

Die simboliserings van die liggaam via die sosialiteit daarvan word deel van 'n gemeenskap se ideologiese wêreld, lê die diepste oortuigings en waardes daarvan bloot, en verskaf so tasbare toegang tot die hart van ' $n$ kultuur. Hierdie konstrukte of simboliserings van die liggaam word dikwels in ' $n$ gemeenskap se letterkundige konstrukte, as deel van die gemeenskap se diskursiewe praktyke, veranker. Dit word deur die gemeenskap se groot verhale of 'metanarratiewe' gedra 'to construct and equip their followers with the status, roles and actions of the different bodies within that specific culture' (Isherwood 2000:9). Die patriargale narratief van die Ou Testament is tipies van so ' $n$ ononderhandelbare meesterverhaal. Hierdie liggaamsimboliserings, wat die gemeenskap se ideale liggaam verteenwoordig, word soms as heel openlike en bedoelde konstrukte in literatuur aangetref, byvoorbeeld in Genesis 1:

Toe het God gesê: "Kom ons maak die mens volgens ons afbeelding, ons beeld, sodat hy kan heers oor die vis in die see, die voëls in die lug, die mak diere, die diere wat op die aarde loop en al die diere wat op die aarde kruip." God het die mens geskep na sy beeld, as beeld van God het Hy die mens geskep, man en vrou het Hy hulle geskep.

(Gen 1:26-27, eie vertaling)

Dus: Om na die mens te kyk, is om God (se liggaam) te sien. Die mens lyk soos God, soos wat God soos die mens lyk.

Ander kere is die liggaamsimboliek verborge; weggesteek as ' $\mathrm{n}$ soort kulturele kode, byvoorbeeld in Genesis 1:

En God het hulle geseën, en God het vir hulle gesê: "Wees vrugbaar en vermeerder en vul die aarde, onderwerp dit en heers oor die visse van die see en die voëls van die hemel en oor al die diere wat op die aarde kruip."

(Gen 1:28)

Verskuil in die konsep 'seën' is die bedoeling van die liggaam as verwekkende entiteit. Om mens te wees, is om soos God te funksioneer wat voortplanting betref. Die simboliese liggaam is voortdurend teenwoordig, veral in die vorm van die ideale of reguleringsliggaam. 


\section{DIE REGULERINGSLIGGAAM}

'Feite en waarhede' wat deur diskoerse oorgedra word, ook die sogenaamde 'meesternarratiewe' van 'n gemeenskap, word tweede natuur; dit word geïnternaliseer, en die proses kan met die aanleer van 'n tegniek vergelyk word (Vorster 1997b:394). Dit word dermate deel van die eienaar, dat dit outomatiese, meganiese gedrag word. So sosialiseer die geïnkorporeerde patriargale narratief byvoorbeeld mans en vroue om sonder bevraagtekening hulle 'regte' plekke in die samelewing in te neem. Dit word eenvoudig deel van 'n gemeenskap se hiërargiese struktuur. Mense weet 'instinktief' wat die regte gedrag in die gemeenskap is, en deur die 'reguleringsliggaam' van jou kultuur uit te leef, hou jy daardie ideale liggaam in stand, en verseker die voortbestaan daarvan. 'Liggame' word dus nie alleen deur ' $n$ kultuur gevorm nie, maar reproduseer en sit sodanige kultuur voort. Vorster (1997b:395-397) skets die uitwerking van ' $\mathrm{n}$ gemeenskap se simboliese 'liggaam' soos volg: Dit vestig beheer oor die liggaam om dit in pas te bring met die waardesisteem van 'n gemeenskap. Hierdie gereguleerde liggaam word dus die 'normale' of aanvaarbare liggaam van ' $n$ kultuur. Voorts word die liggaam ook bemagtig en by ' $n$ bepaalde sosiale struktuur geïntegreer. Die liggaam funksioneer nou binne die parameters van die gemeenskap, en dien die gemeenskap se belange. Deur die herhaling van norme en waardes met betrekking tot die liggaam, word die liggaam 'n 'afsetting' of 'sediment' van daardie herhalings, soms ook in die vorm van rituele praktyke (Butler 1993:16). Liggame materialiseer namate dit deur sosiale norme gereguleer word, en in die proses kom ' $n$ simboliese ideale liggaam, en terselfdertyd ook die simboliese misvormde liggame, tot stand. Hierdie ideale liggaam verkry ' $n$ retoriese aard deur sosiale wisselwerking, want 'persone' is immers sosiale liggame, en funksioneer gevolglik as die reguleerder of die reguleringsliggaam van ' $n$ kultuur. Die ideale of reguleringsliggaam word dus nie maklik bevraagteken nie, maar is die 'erfenis' of die 'kultuur' waarin nuwelinge gebore word; die bril waardeur daar na persone gekyk word, en die norm waaraan alle liggaamlikheid gemeet word. Dit deurdrenk 'n gemeenskap se taal en kommunikasie, en graveer so die ideale liggaamswaardes op die liggame van die gemeenskap. Die reguleringsliggaam word die gemeenskap se ideale kulturele kode waardeur alle ander kodes of konstrukte bepaal word.

Hieruit blyk reeds die mate waarin ' $n$ liggaam se retoriek mag uitoefen oor die persone van 'n kultuur. Wanneer die retoriek van die liggaam, in besonder die reguleringsliggaam, egter in religieuse diskoers tot uiting kom, verkry die liggaam besondere mag. Ander liggame word die plek waarop die hiërargieë, soos wat dit deur die reguleringsliggaam van 'n gemeenskap gerig word, (selfs met geweld, soos uit Vorster 2001 blyk) sigself uitspeel.

\section{DIE GODSKONSTRUK AS REGULERINGSLIGGAAM}

Religieuse diskoers beoog die daarstelling van ideale, paradigmatiese of absolute volmaakte konsepte. Dit is gemoeid met die oprigting van betekeniskonstrukte wat die bestaan van die mensdom sinvol en betekenisvol struktureer. Dit maak aanspraak op die besit van finale betekenis. In navolging van Vorster (2002:11) kan die term 'god' dus as die hoogtepunt en kulminasie van 'n kultuur se linguïstiese hiërargie bestempel word. Die konsepte of strukture, selfs personifikasies, van religieuse diskoerse is dikwels so kragtig dat dit onbetwis aanvaar word, en funksioneer as strukturerende beginsels.

In haar studie van 'geleefde religie' bring Bach (2004:23) die habitus, wat sy as 'the power of cultural structures and inherited idioms' bestempel, nie net met die vorming van die denkpatrone van 'n gemeenskap in verband nie, maar skets sy dit veral as voortbrengingsfaktor; as kreatiewe krag agter godsdienstige vertolking en skeppingsvermoë. Die habitus van 'n gemeenskap - die sieninge, oortuiginge en simboliserings met betrekking tot die ideale liggaam in ' $n$ gemeenskap - kulmineer en het sy grondslag in die konstruksie van 'n god of gode. Die perfekte, hoogste, ideale liggaam word gevind in die persona van die god (Viviers 2005:881). 'n Gemeenskap se god en sy/haar wêreld word op die menslike sosiale wêreld gemodelleer. Om die liggaam van 'n gemeenskap se god waar te neem, ontsluit die begrip van ' $n$ gemeenskap se liggaamsideologie. As kulturele konstruk, gevorm deur die gemeenskap se ideologie en simboliseringsdade, verkry die god van die gemeenskap ook ' $n$ retoriese aard, in die sin dat daardie godskonstruk weer op die liggaam van die gemeenskap, sowel individueel as gesamentlik, ingegrif word, en die ideologie en waardes vorm en slyp.

Godskonstrukte is dus nóg gegewens van buite waaraan 'n gemeenskap bepaalde waarde of mag kan toeken of nie, nóg onskuldige of 'skadelose' figure met wie die lede van 'n gemeenskap hulle 'speels' of met erns en oortuiging kan vereenselwig of nie. Gode is die kulminasie van die sosialewaardesediment grondliggend aan die liggaamsideologie. As geprojekteerde metaforiserings en denkkonstrukte - as 'vergeestelikte' liggaam - verteenwoordig die godskonstruk die gemeenskap se hoogste of uiteindelike waardes, maar ook sy uiterste bemagtigende (of ontmagtigende) hiërargiese hoogtepunt.

Noukeurige studie van 'n gemeenskap se godskonstrukte, byvoorbeeld wat gender betref, behoort dus insig te gee in die waardes wat 'n gemeenskap aanhang, en kan moontlik die weg aanwys tot transformasie ter wille van gendergelykheid en ekobillikheid.

\section{LITERATUURVERWYSINGS}

Ahlers, J., 1990, 'Thinking Like a Mountain: Towards a Sensible Land Ethic', Christian Century 107(14), 433-434, toegang 12 Mei 2006, by http://0-web5.silverplatter.com.raulib. rau. ac.za/webspirs.

Ashbrook, J.B., 1996, 'Toward a New Creation of Being', Zygon 31, 385-399, toegang 10 Maart 2006, by http://0-web5. silverplatter.com.raulib.rau.ac.za/webspirs.

Bach, A., 2004, 'Women's Altars: Lived Religion from Now to Then', in A. Bach, A. Brenner, S. Beigs et al. (reds.), On the Cutting Edge: The Study of Women in Biblical Worlds, pp. 21-35, Continuum, New York.

Basson, A., 2005, 'Divine Metaphors in a Selection of Biblical Hebrew Psalms of Lamentation', D Litt-proefskrif, Universiteit Stellenbosch.

Berquist, J.L., 2002, Controlling Corporeality: The Body and the Household in Ancient Israel, Rutgers University Press, New Brunswick.

Butler, J., 1993, Bodies that Matter: On the Discursive Limits of 'Sex', Routledge, New York.

Isherwood, L., (ed.) 2000, The Good News of the Body: Sexual Theology and Feminism, Sheffield Academic Press, Sheffield.

Johnson, M., 1987, The Body in the Mind: The Bodily Basis of Meaning, Imagination and Reason, The University of Chicago Press, Chicago.

Lakoff, G. \& Johnson, M., 1999, Philosophy in the Flesh: The Embodied Mind and its Challenge to Western Thought, Basic Books, New York.

Leder, D., 1990, The Absent Body, The University of Chicago Press, Chicago.

Malul, M., 2002, Knowledge, Control and Sex. Studies in Biblical Thought, Culture and Worldview, Archaelogical Center Publication, Tel Aviv, Jaffa.

Martin, J.D., 1995, Proverbs, Sheffield Academic Press, Sheffield.

Viviers, H., 2002, 'Body and Nature in Job', Old Testament Essays 14(3), 510-524.

Viviers, H., 2005, 'The Body and Lady Wisdom (Proverbs 1-9)', Old Testament Essays 18(3), 879-890.

Vorster, J.N., 1995, 'Why Opt for a Rhetorical Approach?', Neotestamentica 29(1), 393-418. 
Vorster, J.N., 1997a, 'Construction of Culture through the Construction of Person: The Acts of Thecla as an Example', in S.E. Porter \& T.H. Olbricht (reds.), pp. 445-473, Sheffield Academic Press, Sheffield.

Vorster, J.N., 1997b. 'The Body as Strategy of Power in Religious Discourse', Neotestamentica 31(2), 388-410.

Vorster, J.N., 1998, 'The Study of Religion at the 'Multi-versity': Probing problems and possibilities', Neotestamentica 32(1), 203-240.
Vorster, J.N., 2000, '(E)mpersonating the Bodies of Early Christianity', Neotestamentica 34(1), 103-124.

Vorster,J.N., 2001, "n Politieke Tegnologie van die vroeë Christen se Gepynigde Liggaam', Verbum et Ecclesia 22(2), 434-454.

Vorster, J.N., 2002, 'A Rhetoric of the Body, Praxis and Wisdom', lesing gelewer by OTWSA Kongres, Stellenbosch, Kaapstad, Augustus.

Vorster, J.N., 2003. Wat sê die Bybel regtig oor God?, CB Powell Bybelsentrum, Unisa, Pretoria. 